Santa Cruz, will lead a session on electronic pointof-use instruction;

- and Mignon Adams, Philadelphia College of Pharmacy and Sciences, will address evaluating the instructor.
Registration details will be published in a future issue of C $\& R L$ News. The chair of ACRL's BIS Preconference Committee is Jane Kleiner, Louisiana State University.

\title{
Perfect preservation: A lesson from the past?
}

\author{
By Philip H. Young \\ Library Director \\ University of Indianapolis
}

The library profession is leading the way in identifying an impending crisis which threatens the very roots of modern culture-I refer to the acidic destruction of books. For the last century, the paper used in books, magazines, and newspapers was made with acids which are now causing it to become brittle and to crumble into dust, bearing with it society's recorded knowledge of the last several generations.

Librarians are attempting to avert the cultural suicide of our era by preserving their library collections with the assistance of high technology. Deacidification programs are underway, as are microfilming projects to photograph key items in research collections. Even newer technologies promise other methods of saving the written record of the 20th century, including digitizing it for electronic storage in traditional, magnetic formats or using the new optical wizardry of CD-ROM.

Unfortunately these efforts, though wellintentioned, have proven costly, slow and (worst of all) not really permanent. A deacidified book will still face the mechanical rigors of usage, including dog-eared pages and accidental drops into mudpuddles during a rush to catch a bus. Microfilm, microfiche, and other photographic processes will greatly extend the print's life but are themselves vulnerable to chemical decay of image and file with the eventual loss of viability. Electronic media are also susceptible to long-term decay, as well as to short-term damage. (Who hasn't heard of someone accidentally typing DEL ${ }^{*} \cdot{ }^{*}$ on their computer keyboard?) No one seems to know what the shelf-life of CD-ROM will be, but it is already apparent that surface scratches interfere with image-processing.

Is our effort to preserve the records of our age in vain? Is there no incorruptible medium to which to entrust the essence of our era? Perhaps examining the methods used in earlier ages might provide an insight for us. Since antiquity, writers have used parchment, vellum and other skins, and non-acidic paper for preservation of their musings, but these media, while stable when stored in a monastery or public archives, do not guarantee a lasting record. In ancient times records were also written on bronze, wood and stone. Although wood is clearly impermanent, metal and stone present the desired characteristics of virtual indestructibility. We can read a 6 th-century B.C. treaty of the Greek city Sybaris written on a bronze plate or any of the thousands of imperial Roman tomb inscriptions carved into stone (and now cluttering the world's museums) just as well as at the time of their creation. The written record has been preserved! Unfortunately, however, metal and stone are not inexpensive, easily obtained, rapidly inscribed, or efficiently stored in quantity. Who would want to chisel War and Peace into blocks of marble (or store the result in their library!)?

Happily, research tells us that there is yet another medium used for writing by ancient civilizations which overcomes these problems - the clay tablet. Humanity's earliest surviving documents were imprinted in soft clay, baked to rock-like hardness, and stored for systematic recall (or, as often happened, for posterity.) Do clay tablets meet our needs for writing permanence? They do, indeed, approach indestructibility. Granted, if you drop one, it breaks - but the text is not lost because any archaeologist worth his or her salt can piece it back together, good as new. (Try that with acid paper!) Furthermore, clay is easily and quickly inscribed, unlike metal or stone. It can be found almost anywhere and molded into manageable units for efficient handling and storage. And, most importantly, the writing lasts forever!

My fellow librarians, I submit to you that our preservation efforts have been misdirected. Instead of expensive deacidification, microphotography, electronic or optical conversion, we should be transcribing our hallowed texts onto clay tablets!

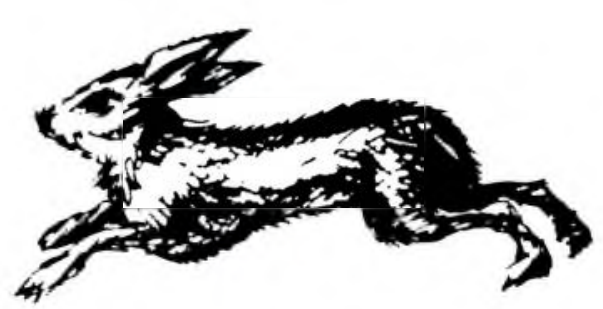

March 1988 / 147 


\section{IT WOULD TAKE YOU AROUND \\ four minutes to boil this egg}

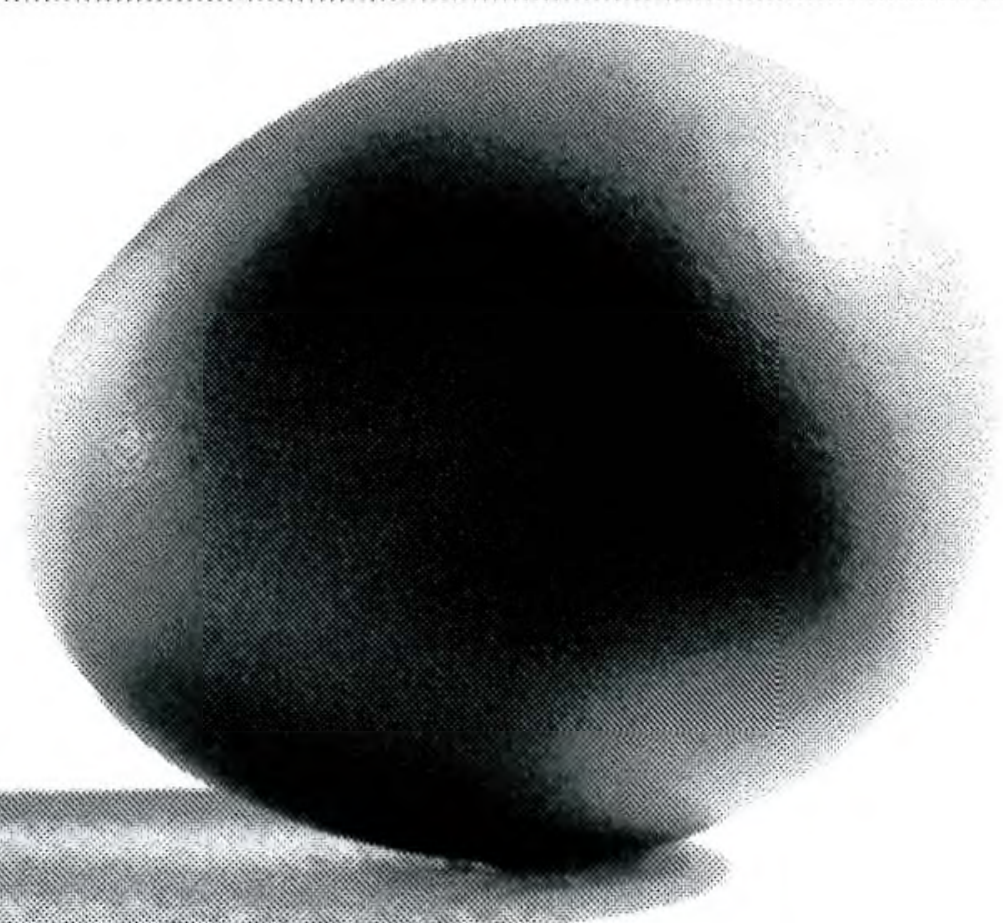

\section{IT WOULD TAKE YOU AROUND sixty seconds to access our million title database via our L/BTEL system}

So why make a meal out of acquiring British academic books?

John Menzies has the perfect recipe. We're based in England and have a database of over 1,000,000 British titles. It takes just 60 seconds to access this database via our LIBTEL system which is available 24 hours a day for the cost of a local telephone call.

LIBTEL provides:

$\square$ Enquiry and pre-order verification on over 1,000,000 British titles.

$\square$ On-line ordering.

$\square$ Hard copy order confirmation and reporting.

We believe that we're faster, more competitive and more reliable than whoever you're currently dealing with and our complete range of Library

Services includes:

$\square$ Comprehensive new title forms service.

$\square$ Subject listings - new and back list titles from our database.

$\square$ Fully automated Periodicals and Continuations subscription service.

John Menzies have been active in book selling since 1833. Today we're part of an international Library Supply Network. Our associates include Coutts Library Services and Readmore in North America as well as Bennetts in Australia.

We're well established, efficient, fast and dependable. We don't just deliver the goods. We deliver the goods quickly. Check us out and see.

To obtain your LIBTEL access code or more information get in touch with Mike Dyche or Jo Buxton in Nottingham now - by phone (collect), Telex, Fax or Electronic Mail.

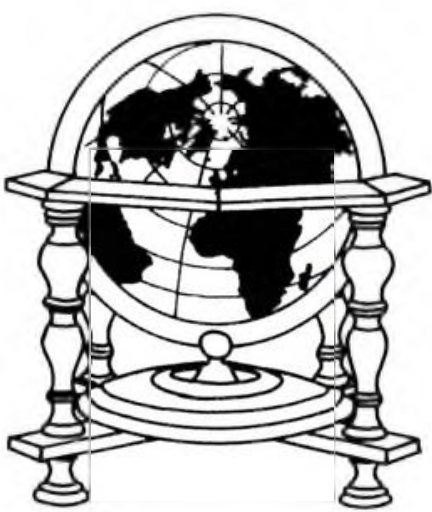

MENZIES

John Menzies

Library Services

24 Gamble Street

Nottingham

NG7 4FJ

England

PH: 602708021

TWX: 37577

JMLSNG G

FAX: 602787718

Electronic mail

OCLC DX: MNZ

W.L.N: MENZ 